\title{
Characterizing Aggregated Exposure to Primary Particulate Matter: Recommended Intake Fractions for Indoor and Outdoor Sources
}

Fantke, Peter; Jolliet, Olivier ; Apte, Joshua Schulz; Hodas, Natasha; Evans, John S. ; Weschler, Charles J.; Stylianou, Katerina S.; Jantunen, Matti J. ; McKone, Thomas Edward

\section{Published in:}

Environmental Science and Technology

Link to article, DOI:

10.1021/acs.est.7b02589

Publication date:

2017

Document Version

Publisher's PDF, also known as Version of record

Link back to DTU Orbit

Citation (APA):

Fantke, P., Jolliet, O., Apte, J. S., Hodas, N., Evans, J. S., Weschler, C. J., Stylianou, K. S., Jantunen, M. J., \& McKone, T. E. (2017). Characterizing Aggregated Exposure to Primary Particulate Matter: Recommended Intake Fractions for Indoor and Outdoor Sources. Environmental Science and Technology, 51(16), 9089-9100. https://doi.org/10.1021/acs.est.7b02589

\section{General rights}

Copyright and moral rights for the publications made accessible in the public portal are retained by the authors and/or other copyright owners and it is a condition of accessing publications that users recognise and abide by the legal requirements associated with these rights.

- Users may download and print one copy of any publication from the public portal for the purpose of private study or research.

- You may not further distribute the material or use it for any profit-making activity or commercial gain

- You may freely distribute the URL identifying the publication in the public portal 


\title{
Characterizing Aggregated Exposure to Primary Particulate Matter: Recommended Intake Fractions for Indoor and Outdoor Sources
}

\author{
Peter Fantke, ${ }^{*}{ }^{\dagger}$ Olivier Jolliet, ${ }^{\ddagger}$ Joshua S. Apte, ${ }^{\S \odot}$ Natasha Hodas, $\|$ John Evans, ${ }^{\perp, \#}$
} Charles J. Weschler, ${ }^{\nabla, \bigcirc}$ Katerina S. Stylianou, ${ }^{\neq}$Matti Jantunen, ${ }^{\triangleright}$ and Thomas E. McKone ${ }^{\mathbb{q}, \infty}$

${ }^{\dagger}$ Quantitative Sustainability Assessment Division, Department of Management Engineering, Technical University of Denmark, Bygningstorvet 116B, 2800 Kgs. Lyngby, Denmark

${ }^{\ddagger}$ School of Public Health, University of Michigan, Ann Arbor, Michigan 48109, United States

${ }^{\S}$ Department of Civil, Architectural and Environmental Engineering, University of Texas at Austin, Austin, Texas 78712, United States

"Division of Chemical Engineering, California Institute of Technology, Pasadena, California 91125, United States

${ }^{\perp}$ Department of Environmental Health, Harvard School of Public Health, Boston, Massachusetts 02115, United States

${ }^{\#}$ Cyprus International Institute for Environment and Public Health, Cyprus University of Technology, 3041 Limassol, Cyprus

${ }^{\nabla}$ Environmental and Occupational Health Sciences Institute, Rutgers University, Piscataway, New Jersey 08854, United States

Onternational Centre for Indoor Environment and Energy, Technical University of Denmark, 2800 Kgs. Lyngby, Denmark

Department of Environmental Health, National Institute for Health and Welfare, 70701 Kuopio, Finland

${ }^{\text {II }}$ School of Public Health, University of California, Berkeley, California 94720, United States

${ }^{\infty}$ Lawrence Berkeley National Laboratory, Berkeley, California 94720, United States

\section{Supporting Information}

ABSTRACT: Exposure to fine particulate matter $\left(\mathrm{PM}_{2.5}\right)$ from indoor and outdoor sources is a leading environmental contributor to global disease burden. In response, we established under the auspices of the UNEP/SETAC Life Cycle Initiative a coupled indoor-outdoor emission-to-exposure framework to provide a set of consistent primary $\mathrm{PM}_{2.5}$ aggregated exposure factors. We followed a matrix-based mass balance approach for quantifying exposure from indoor and ground-level urban and rural outdoor sources using an effective indoor-outdoor population intake fraction and a system of archetypes to represent different levels of spatial detail. Emission-toexposure archetypes range from global indoor and outdoor averages, via archetypal urban and indoor settings, to 3646 real-world cities in 16 parametrized subcontinental regions. Population intake fractions

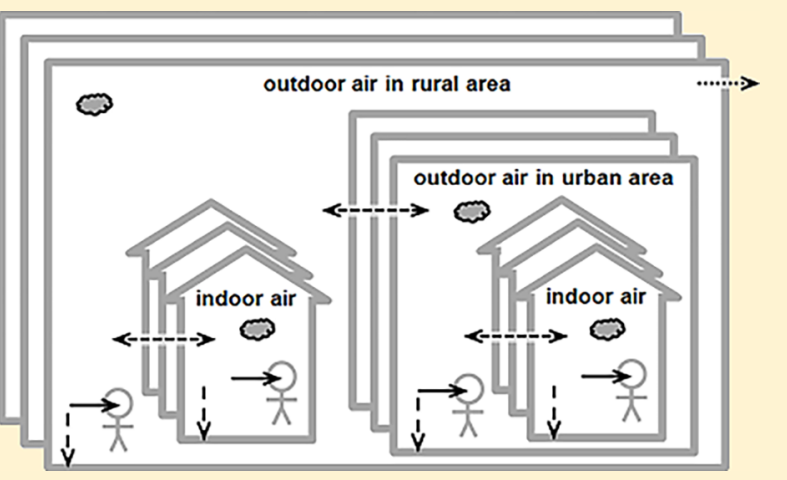
from urban and rural outdoor sources are lowest in Northern regions and Oceania and highest in Southeast Asia with populationweighted means across 3646 cities and 16 subcontinental regions of, respectively, 39 ppm (95\% confidence interval: 4.3-160 $\mathrm{ppm}$ ) and $2 \mathrm{ppm}$ (95\% confidence interval: $0.2-6.3 \mathrm{ppm}$ ). Intake fractions from residential and occupational indoor sources range from $470 \mathrm{ppm}$ to $62000 \mathrm{ppm}$, mainly as a function of air exchange rate and occupancy. Indoor exposure typically contributes $80-90 \%$ to overall exposure from outdoor sources. Our framework facilitates improvements in air pollution reduction strategies and life cycle impact assessments.

\section{INTRODUCTION}

Over the last three decades, multiple epidemiological and toxicological studies have attributed a range of adverse health impacts including chronic and acute respiratory and cardiovascular diseases and premature mortality to exposures to fine particulate matter $\left(\mathrm{PM}_{2.5}\right.$, representing particles with aerodynamic diameter of $2.5 \mu \mathrm{m}$ or smaller) both outdoors and indoors. In the Global Burden of Disease (GBD) study series, exposure to $\mathrm{PM}_{2.5}$ is identified as a leading environmental risk factor contributing to global human disease burden. $\mathrm{PM}_{2.5}$ in outdoor air and household air is reported to contribute to estimated 4.2 and 2.9 million premature deaths, respectively, corresponding to 103 and 86 million disability-adjusted life years (DALY), respectively, in 2015. ${ }^{1,2}$ Indoor and outdoor emissions of primary $\mathrm{PM}_{2.5}$ from anthropogenic sources contribute substantially to human exposures, which take place both indoors and outdoors. Outdoor emissions in urban and

Received: May 19, 2017

Revised: July 6, 2017

Accepted: July 6, 2017

Published: July 6, 2017 
rural areas are mainly associated with road traffic including fuel combustion-related vehicle exhaust and road dust, coal- and gas-fired power plants, and other industrial sources. ${ }^{3,4}$ Indoor emissions in residential, commercial, and occupational settings are mainly from combustion processes (e.g., cooking, smoking, candles). Approximately 2.8 billion people, primarily in Africa and Southeast Asia, are exposed to indoor emissions from the use of solid fuels including coal, charcoal, wood, dung, and crop residues, with substantial impacts on both indoor and outdoor air quality. ${ }^{5-8}$

To inform decisions for comparing and reducing $\mathrm{PM}_{2.5}$ exposure from anthropogenic sources, a quantitative framework is required to link indoor and outdoor environments. Multiple studies have monitored $\mathrm{PM}_{2.5}$ concentrations outdoors ${ }^{9,10}$ and indoors, ${ }^{11,12}$ and estimated related inhalation exposure outdoors $^{13,14}$ and indoors. ${ }^{15,16}$ Intake fractions (population inhalation intake per emission unit) have been determined as related exposure metric either for indoor or for outdoor urban or rural environments. ${ }^{14,17,18}$ However, a consistently coupled indoor-outdoor exposure assessment framework is currently missing that allows for comparing $\mathrm{PM}_{2.5}$-related intake fractions from a range of human activities that lead to outdoor and indoor sources resulting in human exposures to $\mathrm{PM}_{2.5}$ both indoors and outdoors. According to earlier recommendations, ${ }^{19}$ such a framework needs to (a) integrate indoor and outdoor air on a consistent mass-balance basis, thereby accounting for multiple emission sources along product system life cycles, (b) distinguish among relevant emission and exposure scenarios in different indoor, urban and rural outdoor environments, (c) conceptually integrate indoor and outdoor exposure as starting point for linking exposure levels to exposure-response considering that humans spend most of their time indoors, ${ }^{18}$ (d) build on an archetypal structure to capture variability in $\mathrm{PM}_{2.5}$ air concentrations and population density among different indoor and urban- and rural-outdoor environments, and (e) incorporate uncertainty into results at different levels of detail. Hodas et al. ${ }^{18}$ and Milner et al. ${ }^{20}$ further underline the need to include indoor $\mathrm{PM}_{2.5}$ in exposure estimates and to consider distinct archetypes to capture important differences among indoor environments and building types. For outdoor scenarios, spatial approaches are unable to capture higher exposure in urban areas, unless they build on grid-resolutions that allow distinguishing between urban and rural environments in all regions, that is, using resolutions on the order of at least $0.1^{\circ} .^{21,22}$ For example, although intake fractions based on global, spatially gridded $1 \times 1 \mathrm{PM}_{2.5}$ outdoor air concentrations are estimated to only vary between 1.6 and $9.6 \mathrm{ppm}^{23}$ intraurban intake fractions estimated globally for all cities with more than 100000 inhabitants reach $260 \mathrm{ppm}$ with a population-weighted average of $39 \mathrm{ppm}^{14}$ Archetypes are best capable of capturing relevant differences between urban and rural areas, where city-specific intake fractions (e.g., Apte et al. ${ }^{14}$ ) need to be integrated into a background continental environment and account for the fact that the population spends most of its time indoors. ${ }^{18}$ Understanding the interaction between indoor and outdoor environments is also important (for example, when exposure-response functions obtained in a region with low indoor air exchange rates are applied to regions with substantially higher air exchange rates). Therefore, a modeling framework is needed that accounts for various indoor and outdoor settings, interactions between urban and rural areas, and operates at multiple scales of integration, while capturing high variability. ${ }^{24}$
In response to these needs, the United Nations Environment Program/Society of Environmental Toxicology and Chemistry (UNEP/SETAC) Life Cycle Initiative established a task force to provide guidance for quantifying health effects from $\mathrm{PM}_{2.5}$ exposure associated with indoor and outdoor sources for use in life-cycle-based impact assessments. The aim is to compare human activities and product systems with respect to their contribution to $\mathrm{PM}_{2.5}$ emission related disease burden. ${ }^{19,25,26}$ As a first step toward such a $\mathrm{PM}_{2.5}$ impact assessment framework, we aim in the present paper at characterizing for primary $\mathrm{PM}_{2.5}$ the intake fraction, which is the long-term population intake mass per unit mass emitted into different indoor and outdoor environments. Building on the rich literature on $\mathrm{PM}_{2.5}$ exposure research, we organize the present work as follows: First, we structure the $\mathrm{PM}_{2.5}$ emission-to-intake pathway into a system of archetypes representing a tiered approach following different levels of detail for indoor and urban- and rural-outdoor environments. Levels of detail range from generic (global average) level to city-specific level, representing 3646 real-world cities and a set of residential and occupational indoor environments. Second, we describe our system as a fully mass balance based framework for relating indoor and outdoor emissions to aggregate $\mathrm{PM}_{2.5}$ exposure. Third, we analyze the variations of intake fraction among different emission locations in our framework as a function of advection rates and population densities, based on differentiating for each source scenario the contribution of each environment to overall population exposure. Finally, we discuss how the proposed framework is aligned with state-of-the-art indoor- and outdoorexposure models, and how it can be consistently coupled with exposure-response information.

\section{MATERIALS AND METHODS}

Coupled Indoor and Outdoor Source-to-Exposure Framework. Environmental fate and transport processes of $\mathrm{PM}_{2.5}$, linking emissions in different indoor or outdoor environments to human inhalation exposure indoors and outdoors, are represented by a mass balance system of homogeneous air compartments (Figure 1) described by a set of first-order differential equations. In order to address $\mathrm{PM}_{2.5}$ emissions, and complex issues, such as spatially heterogeneous

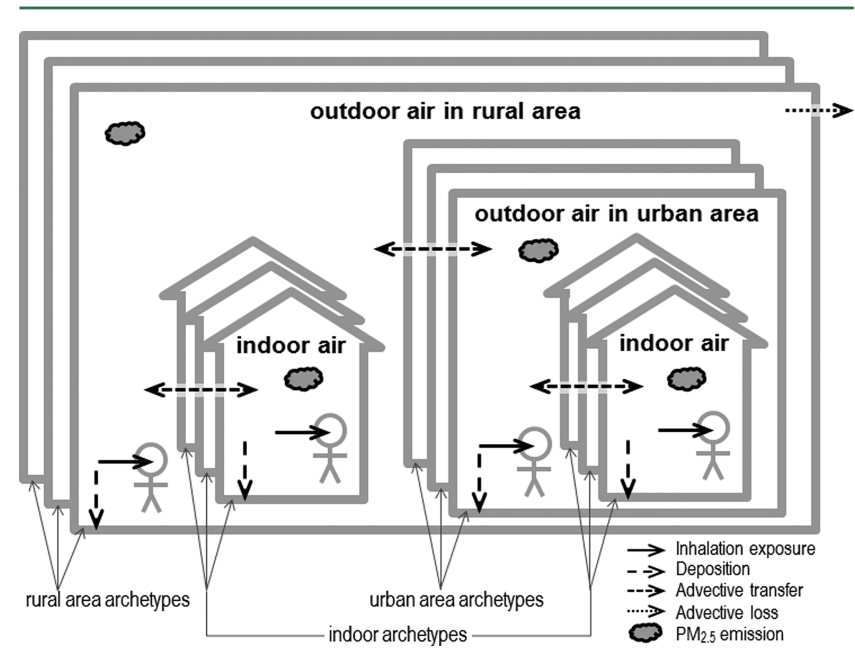

Figure 1. System of distinct archetypes for a set of coupled indoor and outdoor air compartments used for assessing $\mathrm{PM}_{2.5}$ emission-toexposure pathways in urban and rural environments. 
Table 1. Equations to Calculate Fate-Related Rate Coefficients, Human Exposure Factors, And Underlying Parameters Used in the $\mathbf{P M}_{2.5}$ Matrix Framework ${ }^{a}$

variable or parameter

Coefficients for Outdoor Air Compartment in Urban Areas

bulk removal (loss) rate coefficient from outdoor air in urban areas

transfer rate coefficient from outdoor urban air to indoor air in urban areas

transfer rate coefficient from outdoor urban air to outdoor rural air

removal rate coefficient from outdoor urban air via bulk deposition

removal rate coefficient from outdoor urban air via indoor attenuation

removal rate coefficient (exposure factor) from outdoor urban air via inhalation

Coefficients for Outdoor Air Compartment in Rural Areas

bulk removal (loss) rate coefficient from outdoor rural air

transfer rate coefficient from outdoor rural air to indoor air in rural areas

transfer rate coefficient from outdoor rural air to outdoor urban air

advective loss rate coefficient from outdoor rural air to global air

removal rate coefficient from outdoor rural air via bulk deposition

removal rate coefficient from outdoor rural air via indoor attenuation

removal rate coefficient (exposure factor) from outdoor rural air via inhalation

Coefficients for Indoor Air Compartments in Urban and Rural Areas ${ }^{b}$ bulk removal (loss) rate coefficient from indoor air

transfer rate coefficient from indoor air to outdoor air

removal rate coefficient from indoor air via bulk deposition

removal rate coefficient from indoor air via filtration of recirculated air

removal rate coefficient (exposure factor) from indoor air via inhalation equation

$k_{\mathrm{o}, \mathrm{u}, \mathrm{loss}}=k_{\mathrm{i}, \mathrm{u} \leftarrow \mathrm{o}, \mathrm{u}}+k_{\mathrm{o}, \mathrm{r} \leftarrow \mathrm{o}, \mathrm{u}}+k_{\mathrm{o}, \mathrm{u}, \mathrm{dep}}+k_{\mathrm{o}, \mathrm{u}, \mathrm{att}}+\mathrm{XF}_{\mathrm{o}, \mathrm{u}}$

$k_{\mathrm{i}, \mathrm{u} \leftarrow \mathrm{o}, \mathrm{u}}=\frac{k_{\mathrm{o}, \mathrm{u} \leftarrow \mathrm{i}, \mathrm{u}} \times P_{\mathrm{u}} \times V_{\mathrm{i}, \mathrm{u}}}{V_{\mathrm{o}, \mathrm{u}}}$

$k_{\mathrm{o}, \mathrm{r} \leftarrow \mathrm{o}, \mathrm{u}}=\frac{\mathrm{DR}_{\mathrm{o}, \mathrm{u}}}{h_{\mathrm{o}, \mathrm{u}} \times \sqrt{A_{\mathrm{o}, \mathrm{u}}}} \times f_{\mathrm{u}, \mathrm{corr}}$

$k_{\mathrm{o}, \mathrm{u}, \mathrm{dep}}=\frac{v_{\mathrm{o}, \mathrm{u}, \mathrm{dep}}}{h_{\mathrm{o}, \mathrm{u}}}$

$k_{\mathrm{o}, \mathrm{u}, \mathrm{att}}=\frac{A C H_{\mathrm{u}} \times\left(1-P_{\mathrm{u}}\right) \times V_{\mathrm{i}, \mathrm{u}}}{V_{\mathrm{o}, \mathrm{u}}}$

$\mathrm{XF}_{\mathrm{o}, \mathrm{u}}=\frac{\mathrm{BR}_{\mathrm{o}} \times\left(1-f_{t, \mathrm{i}}\right) \times \mathrm{POP}_{\mathrm{u}}}{V_{\mathrm{o}, \mathrm{u}}}$

$k_{\mathrm{o}, \mathrm{r}, \mathrm{loss}}=k_{\mathrm{i}, \mathrm{r} \leftarrow \mathrm{o}, \mathrm{r}}+k_{\mathrm{o}, \mathrm{u} \leftarrow \mathrm{o}, \mathrm{r}}+k_{\mathrm{o}, \mathrm{r}, \mathrm{glob}}+k_{\mathrm{o}, \mathrm{r}, \mathrm{dep}}+k_{\mathrm{o}, \mathrm{r}, \mathrm{att}}+\mathrm{XF}_{\mathrm{o}, \mathrm{r}}$

$k_{\mathrm{i}, \mathrm{r} \leftarrow \mathrm{o}, \mathrm{r}}=\frac{k_{\mathrm{o}, \mathrm{r} \leftarrow \mathrm{i}, \mathrm{r}} \times P_{\mathrm{r}} \times V_{\mathrm{i}, \mathrm{r}}}{V_{\mathrm{o}, \mathrm{r}}}$

$k_{\mathrm{o}, \mathrm{u} \leftarrow \mathrm{o}, \mathrm{r}}=\frac{k_{\mathrm{o}, \mathrm{r} \leftarrow \mathrm{o}, \mathrm{u}} \times V_{\mathrm{o}, \mathrm{u}}}{V_{\mathrm{o}, \mathrm{r}}}$

$k_{\mathrm{o}, \mathrm{r}, \mathrm{glob}}=\frac{u_{\mathrm{o}, \mathrm{r}}}{\sqrt{A_{\mathrm{o}, \mathrm{r}}}}$

$k_{\mathrm{o}, \mathrm{r}, \mathrm{dep}}=\frac{v_{\mathrm{o}, \mathrm{r}, \mathrm{dep}}}{h_{\mathrm{o}, \mathrm{r}}}$

$k_{\mathrm{o}, \mathrm{r}, \mathrm{att}}=\frac{\mathrm{ACH}_{\mathrm{r}} \times\left(1-P_{\mathrm{r}}\right) \times V_{\mathrm{i}, \mathrm{r}}}{V_{\mathrm{o}, \mathrm{r}}}$

$\mathrm{XF}_{\mathrm{o}, \mathrm{r}}=\frac{\mathrm{BR}_{\mathrm{o}} \times\left(1-f_{t, \mathrm{i}}\right) \times \mathrm{POP}_{\mathrm{r}}}{V_{\mathrm{o}, \mathrm{r}}}$

$k_{\mathrm{i}, \text { loss }}=k_{\mathrm{o} \leftarrow \mathrm{i}}+k_{\mathrm{i}, \mathrm{dep}}+k_{\mathrm{i}, \mathrm{circ}}+\mathrm{XF}_{\mathrm{i}}$

$k_{\mathrm{o} \leftarrow \mathrm{i}}=\mathrm{ACH}$

$k_{\mathrm{i}, \mathrm{dep}}=v_{\mathrm{i}, \mathrm{dep}} \times\left(S / V_{\mathrm{i}}\right)$

$k_{\mathrm{i}, \mathrm{circ}}=k_{\text {recirc }} \times \varepsilon_{\text {filter }}$

$\mathrm{XF}_{\mathrm{i}}=\frac{\mathrm{BR}_{\mathrm{i}} \times f_{t, \mathrm{i}} \times \mathrm{POP}}{V_{\mathrm{i}}}$ 


\section{Table 1. continued}

Parameter Used to Calculate Fate-Related Rate Coefficients and Human Exposure Factors

\begin{tabular}{|c|c|}
\hline area of urban areas within any region $x$ & $A_{\mathrm{o}, \mathrm{u}}=\left(\mathrm{POP} \mathrm{u}_{\mathrm{u}} / \mathrm{LPD}\right)^{2}$ \\
\hline volume of indoor air in urban areas & $V_{\mathrm{i}, \mathrm{u}}=V_{\mathrm{i}, \mathrm{u}, \text { pers }} \times \mathrm{POP}_{\mathrm{u}}$ \\
\hline volume of indoor air in rural areas & $V_{\mathrm{i}, \mathrm{r}}=V_{\mathrm{i}, \mathrm{r}, \mathrm{pers}} \times \mathrm{POP}_{\mathrm{r}}$ \\
\hline volume of outdoor air in urban areas & $V_{\mathrm{o}, \mathrm{u}}=A_{\mathrm{o}, \mathrm{u}} \times h_{\mathrm{o}, \mathrm{u}}$ \\
\hline volume of outdoor air in rural areas & $V_{\mathrm{o}, \mathrm{r}}=A_{\mathrm{o}, \mathrm{r}} \times h_{\mathrm{o}, \mathrm{r}}$ \\
\hline correction factor accounting for city-specific dynamics in area and dilution rate & $f_{\mathrm{u}, \text { corr }}=4.95 \times A_{\mathrm{o}, \mathrm{u}}{ }^{0.0508} \times \mathrm{DR}_{\mathrm{o}, \mathrm{u}}{ }^{-0.124}$ \\
\hline \multirow{2}{*}{ penetration factor from outdoor urban air to indoor air in urban areas } & \multirow{2}{*}{$P_{\mathrm{u}}=F_{\mathrm{u}, \text { inf }} \times \frac{k_{\mathrm{i}, \mathrm{u}, \mathrm{dep}}+\mathrm{XF}_{\mathrm{i}, \mathrm{u}}+\mathrm{ACH}_{\mathrm{u}}}{\mathrm{ACH}_{\mathrm{u}}}$} \\
\hline & \\
\hline penetration factor from outdoor rural air to indoor air in rural areas & $P_{\mathrm{r}}=F_{\mathrm{r}, \text { inf }} \times \frac{k_{\mathrm{i}, \mathrm{r}, \mathrm{dep}}+\mathrm{XF}_{\mathrm{i}, \mathrm{r}}+\mathrm{ACH}_{\mathrm{r}}}{\mathrm{ACH}_{\mathrm{r}}}$ \\
\hline
\end{tabular}

${ }^{a}$ Default and constant inputs are provided in the Supporting Information. ${ }^{b}$ Indoor environment equations apply to both urban and rural environments, where relevant parameters, such as population, are environment-specific. ${ }^{c} A$ : air cross section area $\left(\mathrm{m}^{2}\right)$ (see eq 2 for archetypal city areas); ACH: air exchange rate $\left(\mathrm{d}^{-1}\right)$; BR: breathing rate $\left(\mathrm{m}^{3} / \mathrm{d}\right)$; DR: normalized atmospheric dilution rate $\left(\mathrm{m}^{2} / \mathrm{d}\right) ; f_{t, \mathrm{i}}$ : fraction of time per day spent indoors $(-) ; f_{\mathrm{u} \text {,corr }}$ : correction factor accounting for city-specific dynamics in area and dilution rate $(-)$; $F_{\text {inf: }}$ infiltration factor representing an indoor/outdoor air concentration ratio in the absence of indoor sources that is obtained from dividing elements of the fate factors matrix and volumes of the respective indoor and outdoor compartments $(-)$; $h$ : atmospheric mixing height $(\mathrm{m})$; $k$ : first order rate coefficient for individual transfer or bulk removal processes $\left(\mathrm{d}^{-1}\right)$; LPD: linear population density (capita/m) based on Figure 2; $P$ : penetration factor from outdoor to indoor air (-); POP: human population count (capita); $S / V_{\mathrm{i}}$ : total material surface area to air volume ratio indoors $\left(\mathrm{m}^{2} / \mathrm{m}^{3}\right)$; $u$ : $\mathrm{mean}$ wind speed at ground-level $(\mathrm{m} / \mathrm{d}) ; V$ : air volume $\left(\mathrm{m}^{3}\right) ; \nu_{\text {dep }}$ : bulk deposition velocity combining deposition to vertical and upward-facing and downward-facing surfaces $(\mathrm{m} / \mathrm{d})$; XF: human inhalation exposure factor $\left(\mathrm{d}^{-1}\right)$. Indices: i, o, r, u denote indoor, outdoor, rural, and urban, respectively; att, circ, dep, filter, inf, glob, loss, pers, recirc refer to indoor attenuation, air circulation, bulk deposition, air filter, infiltration, global air, bulk removal or loss, per individual person, and air recirculation, respectively; and arrows between indices indicate intercompartment transfer processes.

concentrations in urban environments and different applications of exposure-response functions in indoor, urban, and rural environments based on earlier recommendations, ${ }^{19}$ we made several modifications to existing fate modeling approaches. Most importantly, we couple indoor and outdoor environments, incorporate inhalation as a removal process in the fate model (in addition to using inhalation in the exposure model), and capture exposure-related variability among different indoor, and urban- and rural-outdoor environments. We address variability using a set of interconnected archetypal environments ranging outdoors from global averages of urban conditions to 3646 specific cities and different indoor settings. We finally provide the basis for consistently linking both indoor and outdoor exposure to exposure-response.

The overall source-to-exposure modeling framework builds on four main compartments, namely outdoor and indoor environments in urban and rural areas, where both indoor and outdoor urban environments are nested within rural areas. Figure 1 provides a general illustration of the $\mathrm{PM}_{2.5}$ transport and loss processes considered in and between all compartments. For consistency and completeness we build for each compartment a mass balance equation that addresses emissions; deposition to soil, water, and vegetation surfaces outdoors; advection losses outdoors (including losses beyond the continental rural boundaries to the global atmosphere); transfers between outdoor air and indoor air; deposition to surfaces indoors; removal from indoor environments by cleaning and filtration; and removal by inhalation indoors and outdoors.

Overall Emission-to-Impact Matrix System. Exposurepathway-specific $\mathrm{PM}_{2.5}$ intake fractions relate the population inhaled mass of $\mathrm{PM}_{2.5}$ to the mass emitted and provide the exposure information for the impact assessment framework. Intake fractions are calculated from combining $\mathrm{PM}_{2.5}$ removal via inhalation (exposure factors) with $\mathrm{PM}_{2.5}$ transfer and removal from air (fate factors):

$$
\mathbf{i F}=\mathbf{X F} \mathbf{F F}=\mathbf{X F}\left(-\mathbf{K}^{-1}\right)
$$

where matrix XF $\in \mathbb{R}^{p \times n}$ contains exposure factors expressed as $\mathrm{PM}_{2.5}$ removal rate coefficients (further detailed in Table 1) via inhalation with exposure pathways in rows and receptor compartments in columns, and matrix FF $\in \mathbb{R}^{n \times n}$ contains fate factors representing $\mathrm{PM}_{2.5}$ mass received in receptor compartments (rows) per unit emissions into source compartments (columns). FF main diagonal elements represent $\mathrm{PM}_{2.5}$ residence times, accounting for all multiple intercompartment transfers between the different indoor and outdoor environments. ${ }^{18}$ This allows for assessing not only exposure in the indoor or urban-outdoor emission compartments, but also subsequent exposure after transfer to the continental rural 
environment, which may be especially relevant for small cities. Fate factors for $\mathrm{PM}_{2.5}$ in eq 1 under steady-state conditions are obtained from inverting the matrix of rate coefficients $\mathbf{K} \in \mathbb{R}^{n \times n}$ describing transfers between adjacent compartments and removal (i.e., deposition and inhalation) within compartments. In our framework, matrix $\mathbf{K}$ consists of elements (rate coefficients, $k$ ) representing for outdoor emissions environmental processes within and between four compartments, namely default indoor air in urban (denoted 'i,u') and rural ('i,r') areas and scenario-specific outdoor air in urban ('o, $u$ ') and rural ('o,r') areas, and for indoor emissions environmental processes in a scenario-specific residential or occupational indoor environment. Compartments are further detailed in the following sections. Each main diagonal element of $\mathbf{K}$ represents the bulk removal or loss via all considered processes (denoted "loss" and per convention negative to indicate losses) in the respective compartment and all other nonzero nondiagonal elements represent individual intercompartmental transfers.

Determination of Rate Constants. We focused on adapting and consistently integrating our model elements from existing $\mathrm{PM}_{2.5}$ transport and exposure studies. For addressing transport and fate in outdoor air, we build on an earlier consensus effort ${ }^{17}$ and work by Apte et al., ${ }^{14}$ using respectively a set of parametrized generic (urban and rural) and city-specific archetypes at the global scale. Both studies developed the foundations for our exposure assessment for $\mathrm{PM}_{2.5}$ in outdoor air compartments. While Apte et al. provide a set of theoretical outdoor intake fractions for ground-level emissions in the 3646 cities globally with more than 100000 inhabitants, we linked urban areas to the rural background using 16 subcontinental regions parametrized by Kounina et al. ${ }^{27}$ This ensures full integration of the outdoor environment, while capturing important differences in $\mathrm{PM}_{2.5}$ air concentrations and related intake fractions across urban areas and between urban and rural areas. City-specific dynamics related to area and dilution rate were considered by adjusting the transfer from outdoor urban to rural air in a correction factor as a function of area and dilution rate across cities (see Table 1). This correction factor improves the correlation between intake fraction and the rate coefficient linking the urban area to its background rural environment compared to a direct transfer based only on dilution rate and size of the urban area. ${ }^{14}$ Since our initial correlation makes the fate factor dependent on population density, we recalculated a new correlation of comparable accuracy $\left(R^{2}=0.96\right.$, instead of $\left.R^{2}=0.99\right)$ that uses only the city-specific area and dilution rate as independent variables without involving the linear population density. How we obtained the correction factor is further detailed in the Supporting Information (SI), Section S-2. Differences in atmospheric mixing height are linked to lower dilution rates in urban areas at night and the short residence time of the air in urban areas of only a few hours compared to a longer residence time of air in rural areas of several days, which allows for mixing between day and night over the full mixing height.

For fate factors for indoor emission scenarios, we calculate indoor-to-outdoor transfer fractions to the default outdoor environment, obtaining the removal rates of $\mathrm{PM}_{2.5}$ in different residential and occupational indoor archetypes as a function of ventilation, occupancy, and recirculation/filter efficiency. As a starting point for our indoor transport and fate model, we build on key studies by Thatcher and Layton, ${ }^{28}$ Riley et al., ${ }^{29}$ and Bennett and Furtaw. ${ }^{30}$ For the subsequent exposure assessment indoors and, in particular for exposure from indoor emissions, we build on work by Klepeis et al. ${ }^{31}$ and Weschler and Nazaroff. ${ }^{32}$ In our multimedia framework, we also account for transfer and related exposure to sources emitted elsewhere, primarily building on work by Diapouli et al., ${ }^{33}$ Riley et al., ${ }^{29}$ Thatcher and Layton, ${ }^{28}$ Hänninen et al., ${ }^{34}$ and Meng et al., ${ }^{35}$ assessing $\mathrm{PM}_{2.5}$ exposure indoors attributable to outdoor sources and $\mathrm{PM}_{2.5}$ exposure outdoors attributable to indoor sources. All rate coefficients are further detailed in Table 1, while default model settings are detailed in the SI (Tables S1S2).

We determine exposure factors from indoor and outdoor breathing rates, the fraction of time spent indoors and outdoors, and air volume and population in each compartment, characterizing the fraction of air volume inhaled per day by the compartment-specific population. To arrive at aggregated exposure, intake fractions are calculated separately for each of the interlinked compartments accounting for exposure in all four environments (see Figure 1). For indoor exposure from emissions outdoors in a given region, we parametrize the indoor environment according to the average or most prominent air exchange rate and occupancy in the considered region. For studying emissions in a specific indoor environment when air exchange rates and building occupancies differ from the typical values in the considered region, we created a decoupled indoor model for first calculating the intake fraction attributable to indoor emissions. We then add to this indoor intake fraction the fraction of the indoor emission transferred to the outdoor environment multiplied by the average outdoor intake fraction for the considered region to yield the overall effective intake fractions from indoor sources. The resulting mass-balanced fate and exposure model provides a mathematical framework that builds on state-of-the-art approaches for indoor and outdoor exposure assessment. Accounting for variability within our considered compartments, we introduce criteria described in the following paragraphs for defining consistent sets of archetypal environments for each compartment at generic, regional/intermediary and city-specific levels.

Defining Archetypal Exposure Environments at Different Levels of Detail. We propose a system of archetypes at different levels of detail that provide a higher level of resolution than can be achieved with currently available spatial models. Different levels of detail help to provide exposure estimates that are consistent with available data resolution in different decision contexts. As an example, archetypes at a generic (world average) level are required when emission source location or other scenario details like population density are unknown, ${ }^{17}$ while archetypes at the city level are useful when details about city-specific urban emissions and population density are available. ${ }^{14}$ Criteria for identifying a suitable set of archetypes for each compartment and level of detail help to differentiate and explain variability in emission situations, environmental conditions and human exposure.

In outdoor environments, there is a strong correlation between emission source strength and population density, where it has been shown that intake fractions for $\mathrm{PM}_{2.5}$ emissions from roadways and low stacks can be significantly underestimated by models without very high resolution (at $\mathrm{km}$ scale or finer) emissions-to-population mapping. ${ }^{14,36}$ However, source-specific data on emissions are often unavailable at spatial scales required to account for population heterogeneity across large regions. Archetypes therefore need to capture the essential variability and heterogeneity for providing reliable outdoor intake fraction estimates. 
For a given region, the population and area of a representative city must be defined to match the urban population-weighted average intake fraction of this region, using a population-weighted harmonic mean of the urban atmospheric dilution rate across cities with available data. The relation between population and area must be consistent and reflect the typical population density in cities of a region. This is ensured by studying the region-specific linear population density, LPD (capita/m), which links city area to population in order to determine intake fraction. ${ }^{37}$ To define regionspecific city archetypes, we first establish how LPD varies across cities $i$ as a function of urban population, POP (capita), within each region $x$, with $i \in x$, by fitting a general model $\log \left(\mathrm{LPD}_{i}\right)$ $=\alpha_{x}+\beta \times \log \left(\mathrm{POP}_{i}\right)$ based on 3646 cities from Apte et al. ${ }^{14}$ (see SI, Table S3). Once, this relation is established, we can derive the city area, $A\left(\mathrm{~m}^{2}\right)$, that corresponds to a given POP as follows (see SI, Section S-3):

$$
A=(\mathrm{POP} / \mathrm{LPD})^{2}=\left(10^{-\alpha_{x}} \times \mathrm{POP}_{u}{ }^{1-\beta}\right)^{2}
$$

We distinguish outdoor archetypes at three levels of detail: First, a generic level 1 is defined for situations where emission location or conditions are unknown, reflecting a populationweighted average intake fraction of 39 ppm across 3646 cities. $^{14}$ At finer levels of detail, additional aspects to discriminate intake fractions from outdoor sources are needed, such as different air exchange rates and occupancy levels for indoor environments, city size, spatially differentiated meteorological conditions (dilution rates defined from mixing height and wind speed), and population distribution in relation to emission source distribution for outdoor environments. At intermediate detail level 2, we define average cities to represent urban areas at the level of continental and subcontinental regions ensuring consistency between population, area, and exposure by calculating level 2 outdoor intake fractions as populationweighted averages to provide a surrogate for emission-weighted averages in line with Humbert et al. ${ }^{17}$ and Lobscheid et al. ${ }^{36}$ Finally, if emission scenario information is available for specific cities, we define respective archetypes at level 3 to reflect $\mathrm{PM}_{2.5}$ fate and exposure conditions as precisely as possible, building on available intraurban outdoor intake fractions for 3646 global cities parametrized for city-specific population, area, dilution rate, and $\mathrm{PM}_{2.5}$ background concentration, ${ }^{14}$ and combining these with population, area, and wind speed, based on highresolution spatial data ${ }^{13}$ for rural environments.

For indoor environments, exposure is strongly dependent on air exchange and available volume per person (occupancy). ${ }^{18}$ However, building-specific air exchange and occupancy are usually not available at the level of detail required to account for variabilities across residential and occupational building types in different regions. ${ }^{38}$ Archetypes therefore have to be defined to capture heterogeneity in indoor environments for providing reliable indoor intake fraction estimates. In line with our outdoor archetypes, we distinguish indoor archetypes at three levels of detail: First, a generic level 1 is defined when emission location and building characteristics are unknown, reflecting average exposure conditions under residential indoor settings (see SI, Tables S1, S2). At the intermediate detail level 2, intake fractions are discriminated according to different air exchange rates, occupancies, recirculation rates, and filter efficiencies for residential indoor settings based on Hodas et al., ${ }^{18}$ Rosenbaum et al., ${ }^{39}$ and ASHRAE $62.2,{ }^{40}$ and according to different ventilation rates and occupant densities for occupational indoor settings obtained from ASHRAE 62.1. ${ }^{41}$ Parameterized continental or subcontinental regions are applied at level 2 for outdoor urban and rural environments. Finally, if emission scenarios are available for individual building types, intake fraction estimates at level 3 can be derived from specific air exchange, occupancy, and recirculation/filtration characteristics along with defining the building's specific city or rural area.

\section{RESULTS}

Archetypes for Coupled Outdoor and Indoor Environments. Using archetypes at three levels of detail allows us to develop spatially detailed assessments, while capturing a representative portfolio of buildings, cities and regions. We first consider an outdoor archetype for ground-level emissions, differentiated into urban and rural areas characterized by radial population density. The population of the representative global average city amounts to 2 million inhabitants with a corresponding average linear population density of 141 capita per $\mathrm{m}$ and a population-weighted harmonic mean of the urban atmospheric dilution rate of $420 \mathrm{~m}^{2} / \mathrm{s}$. This corresponds to population-weighted close-to-average meteorological conditions in urban areas and an average relationship between linear population density and population count. Figure 2 shows that

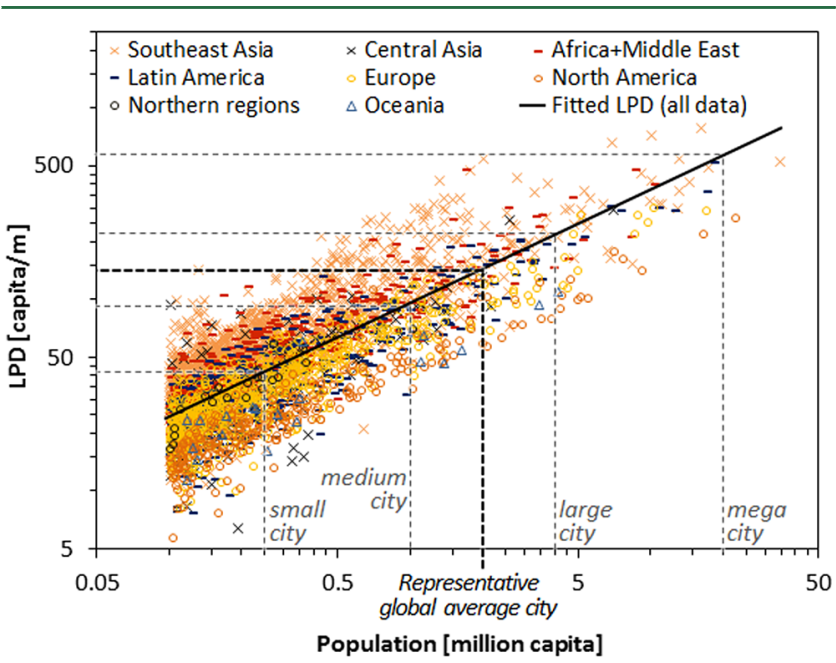

Figure 2. Linear population density (LPD) and population (POP) used for 3646 cities at level 3 grouped according to their corresponding continental region, and location of level 1 representative global average urban archetype, and four example level 2 urban archetypes obtained from fitting $\log (\mathrm{LPD})=-1.494+0.578 \times$ $\log (\mathrm{POP})$ with $R^{2}=0.62$ for the global average intercept and $R^{2}=0.77$ for continent-specific intercepts (provided in SI, Table S3), and common slope.

city-specific linear population density is indeed linearly correlated to city population, with a continent-specific intercept reflecting the variation in urban population density that is highest in Asia and lowest in Australia and North America. This relationship combined with data for parametrized continental or subcontinental regions based on Kounina et al. ${ }^{27}$ is therefore applied at level 2, where the urban archetypes can, for example, be defined to represent small, medium, large, and mega cities as shown in Figure 2 or to identify the population size of a representative average city for each continental and subcontinental region given in Table 2 . When we use the representative average urban area for a given region, the intake fraction is directly obtained from the city population and average dilution rate by the relationship (see SI, Section S-3): 
Table 2. Continental and Sub-Continental Summary Population-Weighted Mean Effective Intake Fractions Including Combined Indoor and Outdoor Exposure from Urban and Rural Outdoor Sources, Number of Cities, Population Count Per Average City Based on PopulationWeighted Effective Intake Fraction, And Population Count in Urban Areas and Totals for Each Region

\begin{tabular}{|c|c|c|c|c|c|}
\hline \multirow[b]{2}{*}{ region } & \multicolumn{2}{|c|}{$\mathrm{iF}(\mathrm{ppm})$} & \multirow[b]{2}{*}{$\begin{array}{c}n \\
\text { (cities) }\end{array}$} & \multicolumn{2}{|c|}{$n$ (million capita) } \\
\hline & $\begin{array}{l}\text { urban } \\
\text { areas }\end{array}$ & $\begin{array}{l}\text { rural } \\
\text { areas }\end{array}$ & & $\begin{array}{l}\text { average } \\
\text { city }\end{array}$ & total \\
\hline global average & 38.6 & 2.2 & 3646 & 2.00 & 6731.67 \\
\hline \multicolumn{6}{|l|}{ Continental Regions } \\
\hline North America & 17.0 & 0.47 & 271 & 2.36 & 334.81 \\
\hline Latin America & 33.7 & 0.51 & 402 & 3.34 & 578.98 \\
\hline Europe & 22.0 & 1.67 & 701 & 1.52 & 751.22 \\
\hline Africa \& Middle East & 40.0 & 1.10 & 466 & 1.44 & 1127.13 \\
\hline Central Asia & 20.7 & 0.60 & 172 & 1.18 & 231.78 \\
\hline Southeast Asia & 57.0 & 4.19 & 1592 & 2.04 & 3666.16 \\
\hline Northern regions & 9.6 & 0.02 & 22 & 0.44 & 16.41 \\
\hline Oceania & 10.1 & 0.04 & 20 & 0.78 & 25.17 \\
\hline \multicolumn{6}{|l|}{ Subcontinental Regions } \\
\hline Central Asia & 20.7 & 0.59 & 172 & 1.13 & 231.78 \\
\hline Indochina & 50.3 & 1.08 & 144 & 2.02 & 360.29 \\
\hline Northern Australia & 3.3 & 0.01 & 2 & 0.29 & 3.06 \\
\hline $\begin{array}{l}\text { Southern Australia \& } \\
\text { New Zealand }\end{array}$ & 10.8 & 0.13 & 18 & 0.77 & 22.11 \\
\hline Southern Africa & 29.3 & 0.72 & 115 & 1.41 & 301.45 \\
\hline $\begin{array}{l}\text { North, West, East \& } \\
\text { Central Africa }\end{array}$ & 40.5 & 1.22 & 351 & 1.36 & 825.68 \\
\hline Argentina+ & 22.2 & 0.23 & 49 & 2.47 & 65.65 \\
\hline Brazil+ & 26.5 & 0.41 & 163 & 2.94 & 236.69 \\
\hline $\begin{array}{l}\text { Central America+ \& } \\
\text { Caribbean }\end{array}$ & 44.1 & 0.63 & 190 & 3.37 & 276.64 \\
\hline USA \& Southern Canada & 17.3 & 0.44 & 271 & 2.25 & 334.81 \\
\hline $\begin{array}{l}\text { Northern Europe \& } \\
\text { Northern Canada }\end{array}$ & 9.6 & 0.01 & 22 & 0.42 & 16.41 \\
\hline Europe & 22.0 & 1.65 & 701 & 1.45 & 751.22 \\
\hline East Indies \& Pacific & 54.6 & 1.12 & 61 & 3.44 & 237.44 \\
\hline India+ & 70.0 & 6.28 & 420 & 3.01 & 1553.18 \\
\hline Eastern China & 40.4 & 3.73 & 808 & 1.26 & 1326.73 \\
\hline Japan \& Korean peninsula & 40.3 & 1.52 & 159 & 3.44 & 188.51 \\
\hline
\end{tabular}

When the size of a representative region-specific urban area needs to be defined, it can be obtained by back-calculating the archetypal population in eq 3 from the weighted populationaverage urban intake fraction (see SI, eq S12). This archetypal population varies from 290000 inhabitants in Northern Australia and 420000 inhabitants in the Northern regions of Canada and Europe up to 3.4 million inhabitants in Central America, Indonesia, Japan and South Korea. At level 3, actual population characteristics based on data for 3646 cities ranging from 100000 to 40 million inhabitants are used for urban areas combined with population and parametrized characteristics of 8 continental or 16 subcontinental regions for rural locations. ${ }^{27}$ The area, $A\left(\mathrm{~m}^{2}\right)$, for cities currently not included in our data set can be obtained as $A=(\mathrm{POP} / \mathrm{LPD})^{2}$ based on known population POP, and LPD estimated from population (see Figure 2 and SI, Table S3). The atmospheric dilution rate that can either be calculated from city-specific wind speed and atmospheric mixing height or, if not available, the default of 420 $\mathrm{m}^{2} / \mathrm{s}$ can be applied as the harmonic average of city-specific dynamics across 3646 cities. For each region/area, such as Indochina (continental Southeast Asia) or Scandinavia, intake fractions in rural areas are weighted by the contribution of each region to total continental emissions.

For the default indoor environments that we defined as baseline for urban and rural areas, we use at level 1 the global default archetype for residential settings. At regionally differentiated outdoor level 2, indoor archetypes are defined according to region-specific air exchange rates and occupancy (room volume per person) without recirculation or filters. For studying emissions into specific indoor environments at level 2, we define archetypes based on low, medium and high air exchange rates and occupancy. We assign these archetypes either no recirculation and no filters or high recirculation rates assuming daily air conditioning system runtime of $20 \%$ (residential settings) and 100\% (occupational settings) coupled with high filter efficiencies based on an average over the range of ASHRAE 52.2 MERV classes 9-12 for "Intended Dust Spot Efficiency" for residential buildings with advanced air-filtration systems. At level 3, specific data for residential and occupational indoor environments or building types can be applied based on data provided by e.g. Hodas et al. ${ }^{18}$

The application of our archetypes to low-stack ( 25 m), high-stack $(\sim 100 \mathrm{~m})$, and very high stack $(\sim 250 \mathrm{~m})$ as well as to secondary $\mathrm{PM}_{2.5}$ formed from precursor emissions will be addressed in a second stage of this research effort. Outdoor and indoor archetype characteristics and model coefficients for level 2 are detailed in the SI (Tables S3-S5).

Effective Intake Fractions and Contributing Source Environments. Figure 3 summarizes the variability across effective population-weighted intake fractions representing aggregated indoor-outdoor exposure for a specific indoor or outdoor source environment.

Across 3646 urban areas with more than 100000 inhabitants, the mean effective population-weighted intake fraction for urban ground-level emissions is $39 \mathrm{ppm}$ (95\% confidence interval: $4.3-160 \mathrm{ppm}$, median $\tilde{x}=26 \mathrm{ppm}$ ). The full range of effective intake fractions across urban source environments spans from 0.9 to $280 \mathrm{ppm}$ with a squared geometric standard deviation $\left(\mathrm{GSD}^{2}\right)$ of 4.7 , indicating that $95 \%$ of all intake fractions fall within the range from $\tilde{x} / \mathrm{GSD}^{2}$ to $\tilde{x} \times \mathrm{GSD}^{2}$. Population-weighted effective intake fractions across urban areas per region, summarized in Table 2, vary from $\sim 10 \mathrm{ppm}$ in Northern regions and Oceania to $57 \mathrm{ppm}$ in Southeast Asia, with India as high-end subcontinental region at $70 \mathrm{ppm}$. This distribution corresponds well with the distribution of effective intake fractions in rural ground-level source environments showing a global mean population-weighted intake fraction of $2.2 \mathrm{ppm}$, ranging from 0.02 in Northern regions with tight buildings (low air exchange) and low occupancy to $4.2 \mathrm{ppm}$ in Southeast Asia with typically high air exchange and high occupancy (95\% confidence interval: $0.2-6.3 \mathrm{ppm}$, median $\tilde{x}=$ 1.7 ppm, GSD $^{2}=6.9$ ) (Table 2). Even for outdoor emissions, between $83 \%$ and $90 \%$ of the intake takes place indoors (see upper label in Figure 3) due to the high fraction of the day spent indoors.

Across indoor source environment archetypes, the mean effective intake fraction is $0.013(13200 \mathrm{ppm})$ for residential settings and 0.017 (17200 ppm) for occupational settings, when the distribution of residential and occupational spaces in the different regions has not been considered. Effective intake fractions across indoor source environments are detailed in Table 3. For buildings without recirculation/filtration, effective 


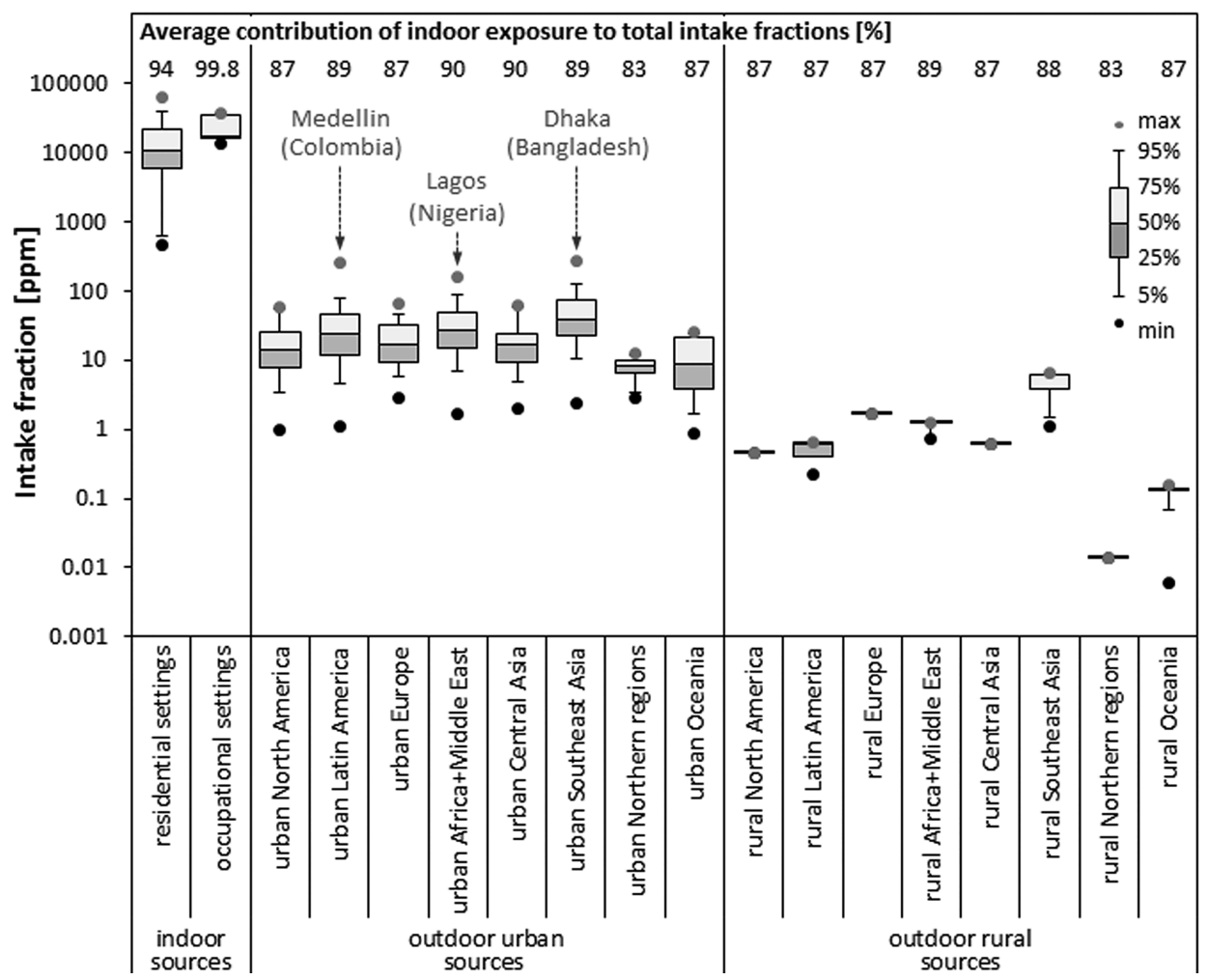

Figure 3. Population-weighted distribution of effective intake fractions $\left(\mathrm{kg} \mathrm{PM}_{2.5}\right.$ inhaled per $\mathrm{kg}_{2.5}$ emitted) and contribution of indoor exposure (percent of total intake fraction) for residential and occupational indoor emission scenarios and for ground-level urban (range over all cities per region) and continental rural outdoor emission scenarios.

Table 3. Summary Total Intake Fractions (ppm) Including Indoor and Outdoor Exposure for Residential and Occupational Indoor Sources with Different Air Exchange Rates, Occupancies and Recirculation/Filtration Settings

\begin{tabular}{|c|c|c|c|c|c|}
\hline \multicolumn{6}{|c|}{ residential settings } \\
\hline & \multicolumn{3}{|c|}{ no recirculation/filtration } & \multicolumn{2}{|c|}{ recirculation/filtration } \\
\hline & $\begin{array}{c}\text { air } \\
\text { exchange } \\
0.21 \mathrm{~h}^{-1}\end{array}$ & $\begin{array}{c}\text { air } \\
\text { exchange } \\
0.62 \mathrm{~h}^{-1}\end{array}$ & $\begin{array}{l}\text { air } \\
\text { xchange } \\
14 \mathrm{~h}^{-1}\end{array}$ & $\begin{array}{c}\text { air } \\
\text { exchange } \\
0.21 \mathrm{~h}^{-1}\end{array}$ & $\begin{array}{c}\text { air } \\
\text { exchange } \\
0.62 \mathrm{~h}^{-1}\end{array}$ \\
\hline $\begin{array}{l}\text { occupancy } \\
100 \mathrm{~m}^{3} / \text { person }\end{array}$ & 19500 & 8890 & 470 & 6900 & 4900 \\
\hline $\begin{array}{l}\text { occupancy } \\
\quad 67 \mathrm{~m}^{3} / \text { person }\end{array}$ & 28900 & 13200 & 730 & 10300 & 7200 \\
\hline $\begin{array}{l}\text { occupancy } \\
30 \mathrm{~m}^{3} / \text { person }\end{array}$ & 62200 & 29000 & 1600 & 22600 & 16000 \\
\hline \multicolumn{6}{|c|}{ occupational settings } \\
\hline \multicolumn{3}{|c|}{ no recirculation/filtration } & \multicolumn{3}{|c|}{ recirculation/filtration } \\
\hline $\begin{array}{l}\text { air exchange } \\
2.7 \mathrm{~L} / \mathrm{s} / \text { capita } \\
\text { occupancy } 5 \\
\text { capita } / 100 \mathrm{~m}^{2}\end{array}$ & $\begin{array}{l}\text { air exchange } \\
8.5 \mathrm{~L} / \mathrm{s} / \text { capita } \\
\text { occupancy } 5 \\
\text { capita/100 m }\end{array}$ & $\begin{array}{l}\text { air exchange } \\
13 \mathrm{~L} / \mathrm{s} / \text { capita } \\
\text { occupancy } 10 \\
\text { capita/100 m }\end{array}$ & $\begin{array}{l}\text { air ex } \\
2.7 \mathrm{~L} / \\
\text { occul } \\
\text { capita }\end{array}$ & $\begin{array}{l}\text { hange } \\
\text { /capita } \\
\text { ancy } 5 \\
100 \mathrm{~m}^{2}\end{array}$ & $\begin{array}{l}\text { air exchange } \\
8.5 \mathrm{~L} / \mathrm{s} / \text { capita } \\
\text { occupancy } 5 \\
\text { capita/100 } \mathrm{m}^{2}\end{array}$ \\
\hline 37300 & 17200 & 13000 & & 50 & 2950 \\
\hline
\end{tabular}

intake fractions range over 3 orders of magnitude from 470 ppm in regions where buildings have high air exchange and low occupancy to $62200 \mathrm{ppm}$ in regions where buildings have low air exchange and high occupancy. Indoor exposure contributes $91-99 \%$ to effective intake fractions across indoor source environments and is highest for conditions with high occupancy, low air exchange, and recirculation/filtration of indoor air. Generally, we observe that for an emission into urban areas, rural background exposure becomes important for small cities with low urban intake fractions especially in India and eastern China with respective rural intake fractions of 6.3 and $3.7 \mathrm{ppm}$. In such situations, neglecting the rural background leads to an underestimation of the effective exposure from emissions to urban areas by up to $81 \%$.

Overall, our exposure estimates are in line with results from previous work. ${ }^{14,17}$ However, the population-weighted ratio of our effective total intake fractions for outdoor urban sources and outdoor urban intake fractions from Apte et al. ${ }^{14}$ is 0.9 , and ranges from 0.5 in Yakutsk (Russia) to $1.5 \mathrm{La} \mathrm{Paz}$ (Bolivia). This means that intake fractions are effectively slightly reduced on average when accounting for indoor exposure attributable to outdoor sources, especially where removal from outdoor air is driven by air exchange. This is mainly the case in regions with generally low air exchange rates and low rural background exposure with an average ratio of effective intake fractions combining indoor and outdoor exposure to theoretical outdoor intake fractions of only 0.55 across cities in Northern regions, while no reduction in intake fractions is seen when air exchange is high. Furthermore, effective indoor-outdoor intake fractions exceed outdoor intake fractions in urban source environments where air exchange is high and additionally where background exposure is high in related rural environments, which is generally the case in Indochina, India, and Africa.

\section{DISCUSSION}

$\mathrm{PM}_{2.5}$ Framework Applicability and Limitations. In summary, our source-to-exposure framework provides for the first time a modular, fully mass balanced and flexible approach to combine $\mathrm{PM}_{2.5}$ exposure indoors and outdoors from emissions to residential or occupational indoor, and urbanand rural-outdoor environments. This approach provides a sound basis for integrating $\mathrm{PM}_{2.5}$ exposure assessment with 
finally be translated into human intake dose, accounting for breathing rates under different exposure situations.

Future Research Needs. In developing $\mathrm{PM}_{2.5}$ intake fractions, four pollutant species need to be considered: emissions of primary $\mathrm{PM}_{2.5}$; formation of secondary $\mathrm{PM}_{2.5}$ from emissions of precursor substances $\mathrm{SO}_{2}, \mathrm{NO}_{x}$, and $\mathrm{NH}_{3}$ (as ammonium sulfate and ammonium nitrate); and secondary organic aerosols (SOA) resulting from emissions of biogenic and anthropogenic precursors. Furthermore, in some urban environments, it is necessary to address the interaction of volatile organic compounds (VOCs) and ozone with $\mathrm{NO}_{x}$ in forming secondary $\mathrm{PM}_{2.5}$. While our framework currently considers primary $\mathrm{PM}_{2.5}$, it needs modifications to account for the contribution of secondary $\mathrm{PM}_{2.5}$ formed outdoors ${ }^{46}$ and indoors ${ }^{47}$ to indoor and outdoor exposures. For outdoor environments, source- and pollutant-specific global data on stack height are needed in addition to ground-level emission profiles based on, for example, Pregger and Friedrich ${ }^{48}$ for Europe. Our data for urban areas are currently in the domain of cities with more than 100000 inhabitants, whereas atmospheric dilution and the population-linear population density relation require further research for smaller cities where the influence of rural background exposure might become more relevant. Compared to the high resolution of urban areas we apply a resolution in rural areas only at the level of subcontinents, as variability in intake fraction is generally lower in rural areas compared to variability in intake fractions between cities or between urban and rural environments. This approach is supported by studies obtaining a relatively small variability also from higher resolution estimates of intake fractions that are in addition at the low exposure range. ${ }^{23,49}$ This low variability is expected to increase dramatically when the application moves to high-population density urban areas. For background exposure to emissions in urban areas, our resolution for rural environments is hence reasonable, whereas the variability in exposure to emissions in very remote areas might be somewhat underestimated and requires additional study.

For indoor environments, factors for near-person resuspension of $\mathrm{PM}_{2.5}$ deposited indoors as well as $\mathrm{PM}_{2.5}$ formed as a result of near-person chemistry need to be developed. ${ }^{50}$ This may be especially important in the instance of high indoor person density and low air movement, where complete mixing cannot be assumed. Such factors could be derived from calibrating near-person airflow using computational fluid dynamics (CFD) modeling for different types of indoor sources. Furthermore, to improve the accuracy of indoor exposure estimates, the fraction of buildings with different air exchange rates and occupancies and the population fractions in these building archetypes need to be assessed. This is especially relevant for outdoor source scenarios, since most of the affected population is indoors, while this aspect is less relevant when assessing indoor sources occurring in individual buildings.

Currently, our framework can help to better characterize exposure across multiple geographic and scenario scales based on available levels of data. It can be used as a tool in air pollution reduction strategies to evaluate trade-offs among emission sources in different indoor and outdoor settings of urban and rural environments. It can also aid in evaluating the environmental performance of products and services in life cycle impact assessment (LCIA) with respect to life cycle emissions that contribute to $\mathrm{PM}_{2.5}$ population exposures.

\section{ASSOCIATED CONTENT}

\section{Supporting Information}

The Supporting Information is available free of charge on the ACS Publications website at DOI: 10.1021/acs.est.7b02589.

Input parameters for emission-to-exposure archetypes, correction of outdoor urban to rural air transfer, and fitting urban population and area from representative exposure levels are provided in a supporting document (PDF)

The fully operational emission-to-exposure $\mathrm{PM}_{2.5}$ model including the matrix calculation framework, archetypes and spatial background data is provided as macroenabled Microsoft Excel workbook (ZIP)

\section{AUTHOR INFORMATION}

\section{Corresponding Author}

*Phone: +45 45254452; fax: +45 45933435; e-mail: pefan@ dtu.dk.

ORCID $\odot$

Peter Fantke: 0000-0001-7148-6982

Joshua S. Apte: 0000-0002-2796-3478

\section{Notes}

The authors declare no competing financial interest.

\section{ACKNOWLEDGMENTS}

We thank Jeffrey Siegel, Deborah Bennett, Jouni Tuomisto, Marko Tainio, and Michael Brauer for their manuscript comments and data inputs. This work was financially supported by the UNEP/SETAC Life Cycle Initiative and by the Marie Curie project Quan-Tox (grant agreement no. 631910) funded by the European Commission under the Seventh Framework Programme.

\section{REFERENCES}

(1) Forouzanfar, M. H.; Afshin, A.; Alexander, L. T.; Anderson, H. R.; Bhutta, Z. A.; Biryukov, S.; et al. Global, regional, and national comparative risk assessment of 79 behavioural, environmental and occupational, and metabolic risks or clusters of risks, 1990-2015: A systematic analysis for the Global Burden of Disease Study 2015. Lancet 2016, 388, 1659-1724.

(2) Cohen, A. J.; Brauer, M.; Burnett, R.; Anderson, H. R.; Frostad, J.; Estep, $\mathrm{K}_{\text {.; }}$ et al. Estimates and 25-year trends of the global burden of disease attributable to ambient air pollution: An analysis of data from the Global Burden of Diseases Study 2015. Lancet 2017, 389, 19071918.

(3) Cassee, F. R.; Héroux, M.-E.; Gerlofs-Nijland, M. E.; Kelly, F. J. Particulate matter beyond mass: Recent health evidence on the role of fractions, chemical constituents and sources of emission. Inhalation Toxicol. 2013, 25, 802-812.

(4) Laden, F.; Neas, L. M.; Dockery, D. W.; Schwartz, J. Association of fine particulate matter from different sources with daily mortality in six U.S. cities. Environ. Health Perspect. 2000, 108, 941-947.

(5) Chafe, Z. A.; Brauer, M.; Klimont, Z.; Van Dingenen, R.; Mehta, S.; Rao, S.; Riahi, K.; Dentener, F.; Smith, K. R. Household cooking with solid fuels contributes to ambient $\mathrm{PM}_{2.5}$ air pollution and the burden of disease. Environ. Health Perspect. 2014, 122, 1314-1320.

(6) Bonjour, S.; Adair-Rohani, H.; Wolf, J.; Bruce, N. G.; Mehta, S.; Prüss-Ustün, A.; Lahiff, M.; Rehfuess, E. A.; Mishra, V.; Smith, K. R. Solid fuel use for household cooking: Country and regional estimates for 1980-2010. Environ. Health Perspect. 2013, 121, 784-790.

(7) Liu, J.; Mauzerall, D. L.; Chen, Q.; Zhang, Q.; Song, Y.; Peng, W.; Klimont, Z.; Qiu, X.; Zhang, S.; Hu, M.; Lin, W.; Smith, K. R.; Zhu, T. Air pollutant emissions from Chinese households: A major and 
underappreciated ambient pollution source. Proc. Natl. Acad. Sci. U. S. A. 2016, 113, 7756-7761.

(8) Butt, E. W.; Rap, A.; Schmidt, A.; Scott, C. E.; Pringle, K. J.; Reddington, C. L.; et al. The impact of residential combustion emissions on atmospheric aerosol, human health, and climate. Atmos. Chem. Phys. 2016, 16, 873-905.

(9) van Donkelaar, A.; Martin, R. V.; Brauer, M.; Boys, B. L. Use of satellite observations for long-term exposure assessment of global concentrations of fine particulate matter. Environ. Health Perspect. 2015, 123, 135-143.

(10) Philip, S.; Martin, R. V.; van Donkelaar, A.; Lo, J. W.-H.; Wang, Y.; Chen, D.; Zhang, L.; Kasibhatla, P. S.; Wang, S.; Zhang, Q.; Lu, Z.; Streets, D. G.; Bittman, S.; Macdonald, D. J. Global chemical composition of ambient fine particulate matter for exposure assessment. Environ. Sci. Technol. 2014, 48, 13060-13068.

(11) Long, C. M.; Suh, H. H.; Koutrakis, P. Characterization of indoor particle sources using continuous mass and size monitors. J. Air Waste Manage. Assoc. 2000, 50, 1236-1250.

(12) Brown, K. W.; Sarnat, J. A.; Koutrakis, P. Concentrations of $\mathrm{PM}_{2.5}$ mass and components in residential and non-residential indoor microenvironments: The Sources and Composition of Particulate Exposures study. J. Exposure Sci. Environ. Epidemiol. 2012, 22, 161172.

(13) Brauer, M.; Freedman, G.; Frostad, J.; van Donkelaar, A.; Martin, R. V.; Dentener, F.; et al. Ambient air pollution exposure estimation for the Global Burden of Disease 2013. Environ. Sci. Technol. 2016, 50, 79-88.

(14) Apte, J. S.; Bombrun, E.; Marshall, J. D.; Nazaroff, W. W. Global intraurban intake fractions for primary air pollutants from vehicles and other distributed sources. Environ. Sci. Technol. 2012, 46, 3415-3423.

(15) Gao, J.; Cao, C.; Luo, Z.; Zhang, X. Inhalation exposure to particulate matter in rooms with underfloor air distribution. Indoor Built Environ. 2014, 23, 236-245.

(16) Li, T.; Cao, S.; Fan, D.; Zhang, Y.; Wang, B.; Zhao, X.; Leaderer, B. P.; Shen, G.; Zhang, Y.; Duan, X. Household concentrations and personal exposure of $\mathrm{PM}_{2.5}$ among urban residents using different cooking fuels. Sci. Total Environ. 2016, 548-549, 6-12.

(17) Humbert, S.; Marshall, J. D.; Shaked, S.; Spadaro, J. V.; Nishioka, Y.; Preiss, P.; McKone, T. E.; Horvath, A.; Jolliet, O. Intake fraction for particulate matter: Recommendations for life cycle impact assessment. Environ. Sci. Technol. 2011, 45, 4808-4816.

(18) Hodas, N.; Loh, M.; Shin, H.-M.; Li, D.; Bennett, D.; McKone, T. E.; Jolliet, O.; Weschler, C. J.; Jantunen, M.; Lioy, P.; Fantke, P. Indoor inhalation intake fractions of fine particulate matter: Review of influencing factors. Indoor Air 2016, 26, 836-856.

(19) Fantke, P.; Jolliet, O.; Apte, J. S.; Cohen, A. J.; Evans, J. S.; Hänninen, O. O.; Hurley, F.; Jantunen, M. J.; Jerrett, M.; Levy, J. I.; Loh, M. M.; Marshall, J. D.; Miller, B. G.; Preiss, P.; Spadaro, J. V.; Tainio, M.; Tuomisto, J. T.; Weschler, C. J.; McKone, T. E. Health effects of fine particulate matter in life cycle impact assessment: Conclusions from the Basel guidance workshop. Int. J. Life Cycle Assess. 2015, 20, 276-288.

(20) Milner, J.; Vardoulakis, S.; Chalabi, Z.; Wilkinson, P. Modelling inhalation exposure to combustion-related air pollutants in residential buildings: Application to health impact assessment. Environ. Int. 2011, 37, 268-279.

(21) Li, Y.; Henze, D. K.; Jack, D.; Kinney, P. L. The influence of air quality model resolution on health impact assessment for fine particulate matter and its components. Air Qual., Atmos. Health 2016, 9, 51-68.

(22) Punger, E. M.; West, J. J. The effect of grid resolution on estimates of the burden of ozone and fine particulate matter on premature mortality in the United States. Air Qual., Atmos. Health 2013, 6, 563-573.

(23) van Zelm, R.; Preiss, P.; van Goethem, T.; Van Dingenen, R.; Huijbregts, M. Regionalized life cycle impact assessment of air pollution on the global scale: Damage to human health and vegetation. Atmos. Environ. 2016, 134, 129-137.
(24) NRC National Research Council. Exposure Science in the 21st Century: A Vision and a Strategy; Washington, DC, 2012.

(25) Frischknecht, R.; Fantke, P.; Tschümperlin, L.; Niero, M.; Antón, A.; Bare, J.; et al. Global guidance on environmental life cycle impact assessment indicators: Progress and case study. Int. J. Life Cycle Assess. 2016, 21, 429-442.

(26) Jolliet, O.; Frischknecht, R.; Bare, J.; Boulay, A.-M.; Bulle, C.; Fantke, P.; et al. Global guidance on environmental life cycle impact assessment indicators: Findings of the scoping phase. Int. J. Life Cycle Assess. 2014, 19, 962-967.

(27) Kounina, A.; Margni, M.; Shaked, S.; Bulle, C.; Jolliet, O. Spatial analysis of toxic emissions in LCA: A sub-continental nested USEtox model with freshwater archetypes. Environ. Int. 2014, 69, 67-89.

(28) Thatcher, T. L.; Layton, D. W. Deposition, resuspension, and penetration of particles within a residence. Atmos. Environ. 1995, 29, 1487-1497.

(29) Riley, W. J.; McKone, T. E.; Lai, A. C. K.; Nazaroff, W. W. Indoor particulate matter of outdoor origin: Importance of sizedependent removal mechanisms. Environ. Sci. Technol. 2002, 36, 200207.

(30) Bennett, D. H.; Furtaw, E. J. Fugacity-based indoor residential pesticide fate model. Environ. Sci. Technol. 2004, 38, 2142-2152.

(31) Klepeis, N. E.; Ott, W. R.; Switzer, P. A multiple-smoker model for predicting indoor air quality in public lounges. Environ. Sci. Technol. 1996, 30, 2813-2820.

(32) Weschler, C. J.; Nazaroff, W. W. SVOC exposure indoors: Fresh look at dermal pathways. Indoor Air 2012, 22, 356-377.

(33) Diapouli, E.; Chaloulakou, A.; Koutrakis, P. Estimating the concentration of indoor particles of outdoor origin: A review. J. Air Waste Manage. Assoc. 2013, 63, 1113-1129.

(34) Hänninen, O.; Hoek, G.; Mallone, S.; Chellini, E.; Katsouyanni, K.; Gariazzo, C.; Cattani, G.; Marconi, A.; Molnár, P.; Bellander, T.; Jantunen, M. Seasonal patterns of outdoor PM infiltration into indoor environments: review and meta-analysis of available studies from different climatological zones in Europe. Air Qual., Atmos. Health 2011, 4, 221-233.

(35) Meng, Q. Y.; Turpin, B. J.; Lee, J. H.; Polidori, A.; Weisel, C. P.; Morandi, M.; Colome, S.; Zhang, J.; Stock, T.; Winer, A. How does infiltration behavior modify the composition of ambient $\mathrm{PM}_{2.5}$ in indoor spaces? An analysis of RIOPA data. Environ. Sci. Technol. 2007, $41,7315-7321$

(36) Lobscheid, A. B.; Nazaroff, W. W.; Spears, M.; Horvath, A.; McKone, T. E. Intake fractions of primary conserved air pollutants emitted from on-road vehicles in the United States. Atmos. Environ. 2012, 63, 298-305.

(37) Marshall, J. D. Urban land area and population growth: A new scaling relationship for metropolitan expansion. Urban Stud. 2007, 44, $1889-1904$

(38) Nazaroff, W. W. Getting the magnitude right. Indoor Air 2014, 24, 337-338.

(39) Rosenbaum, R. K.; Meijer, A.; Demou, E.; Hellweg, S.; Jolliet, O.; Lam, N. L.; Margni, M.; McKone, T. E. Indoor air pollutant exposure for life cycle assessment: Regional health impact factors for households. Environ. Sci. Technol. 2015, 49, 12823-12831.

(40) ASHRAE. ANSI/ASHRAE Standard 62.2-2013 - Ventilation and Acceptable Indoor Air Quality in Low-Rise Residential Buildings; Atlanta, GA, 2013.

(41) ASHRAE. ANSI/ASHRAE Standard 62.1-2013 - Ventilation for Acceptable Indoor Air Quality; Atlanta, GA, 2013.

(42) Lai, A. C. K.; Nazaroff, W. W. Modeling indoor particle deposition from turbulent flow onto smooth surfaces. J. Aerosol Sci. 2000, 31, 463-476.

(43) Angel, S.; Parent, J.; Civco, D. L.; Blei, A.; Potere, D. The dimensions of global urban expansion: Estimates and projections for all countries, 2000-2050. Prog. Plann. 2011, 75, 53-107.

(44) Gronlund, C. J.; Humbert, S.; Shaked, S.; O’Neill, M. S.; Jolliet, O. Characterizing the burden of disease of particulate matter for life cycle impact assessment. Air Qual., Atmos. Health 2015, 8, 29-46. 
(45) Burnett, R. T.; Pope, C. A., III; Ezzati, M.; Olives, C.; Lim, S. S.; Mehta, S.; et al. An integrated risk function for estimating the global burden of disease attributable to ambient fine particulate matter exposure. Environ. Health Perspect. 2014, 122, 397-403.

(46) Tessum, C. W.; Hill, J. D.; Marshall, J. D. InMAP: A new model for air pollution interventions. Geosci. Model Dev. Discuss. 2015, 8, 9281-9321.

(47) Waring, M. S. Secondary organic aerosol in residences: Predicting its fraction of fine particle mass and determinants of formation strength. Indoor Air 2014, 24, 376-389.

(48) Pregger, T.; Friedrich, R. Effective pollutant emission heights for atmospheric transport modelling based on real-world information. Environ. Pollut. 2009, 157, 552-560.

(49) Humbert, S.; Manneh, R.; Shaked, S.; Wannaz, C.; Horvath, A.; Deschênes, L.; Jolliet, O.; Margni, M. Assessing regional intake fractions in North America. Sci. Total Environ. 2009, 407, 4812-4820. (50) Ferro, A. R.; Kopperud, R. J.; Hildemann, L. M. Source strengths for indoor human activities that resuspend particulate matter. Environ. Sci. Technol. 2004, 38, 1759-1764. 